\title{
The Effect of Geosynthetic Content on Soil Behaviour
}

\author{
Hemant Sharma \\ Assistant Professor, Department of Civil Engineering, K J Institute of Engineering \& Technology, Savli, Gujarat, \\ India
}

\begin{abstract}
While designing structure that will impose a significant load over a larger area, Geotechnical address the following situations especially when dealing with weak foundation in soil, bearing capacity failure, differential settlement and soil instability. The objective of this study is to investigate and evaluate the benefits of inclusion of carbon fibre and it's composite. The acceptance of carbon fibre in reinforced soil construction has been triggered by no of factors including light weight, economical, tolerate large deformation, high stiffness, high temperature tolerance. So here is the attempt to present the details of investigation of the performance of geosynthetic reinforcement on soil to increase bearing capacity.
\end{abstract}

Keywords : Geosynthetics, Geogrid, Shear Strength, Tension Strength, CBR Test, Proctor compaction Test

\section{INTRODUCTION}

Soil alone is able to carry only compressive and shear forces. However, through the use of geosynthetics as reinforcing elements, soil structures can be built to carry tensile forces. It's a actual vision that the reinforcement of soil with geogrids will be as common in the future as the reinforcement of concrete with steel mesh is today. Today, it is already state-of-the-art for earthworks or base courses in road works or railway projects to be reinforced with geosynthetics. Like reinforced concrete, the technical properties of soil can also be considerably improved in combination with geosynthetics, as geosynthetic reinforcement materials will absorb tensile forces. The a fore mentioned advantages provided by geosynthetic-reinforced structures are meeting with increasing acceptance the world over, and this trend is further supported by their excellent track record regarding, e.g., seismic loading. Irrespective of normal traffic load and stress in normal usage, under sudden seismic stress, the original short-term strength of geosynthetic reinforcement products comes into its own to provide a valuable source of working load reserves in the case of a catastrophe. In road or railway applications the insertion of horizontal geogrid layers in granular base courses provides an increased modulus, hence a lateral confinement to the system.

This reinforcing effect will also lead to the longer service life of traffic structures, but it's very difficult to show this improvement by a simple plate loading test. More research is still needed and necessary. In addition, geogrid reinforced traffic areas can avoid massive soil exchanges by improving the in situ (existing) soil with the reinforcement. Geogridreinforced soil structures as a flexible alternative to conventional construction methods, e.g., concrete retaining walls, also allow for the preparation of land for building even under difficult topographic conditions.

Geogrid-reinforced steep slopes enable the development of land for building on a limited space, which is extremely beneficial in the case of expensive 
land prices. From an economical viewpoint, a reduction in the overall construction costs of at least $30 \%$ can be achieved compared to conventional methods.

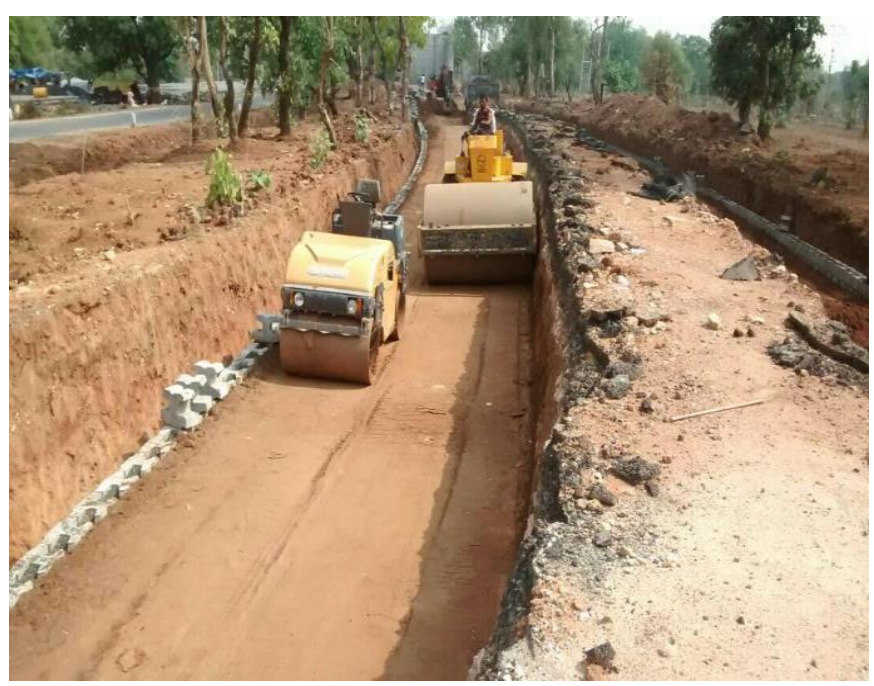

Fig 1. Geosynthetic Compaction

The current design procedure for appropriate constructions is based on classical soil mechanics and, up to now, has not adequately taken the visco-elastic properties of geosynthetic reinforcement materials and the effects of geosynthetic/soil composites or geosynthetic soil interaction into account. But it has been proven that the present design procedure for reinforced earth constructions comprises quite considerable and reassuring safety reserves, which also contribute in furthering the acceptance of such structures. For loading the structure, a big counter pressure rig was installed on the top level of the structure, and the reaction forces were taken by big steel reinforced anchor piles. Reaching more than 20 times the calculated design load of the geogrid reinforced structure, the anchor piles failed, but the geogrid-reinforced structure did not even move (Bräu \& Floss, 2000). Optimized design procedures and the improved utilization of geosynthetic reinforcement products will distinctly increase the economic benefits of this method of construction even more. Increased research work on this issue is desirable, particularly in the interest of public building authorities. Constructing steeper cut and fill sections, bridge abutments and noise protection walls, frequently in conjunction with smaller areas and/or less land acquisition, should be consistently made use of as options well in line with even tighter public budgets.

\section{Reinforced Base/Subbase Design}

Geogrids have been used for reinforcement of aggregate layers within the pavement system since their introduction in the early 1980s. The predominant reinforcing mechanism associated with this application is base course lateral restraint. The base course lateral restraint develops through interlock between the aggregate, soil and the geogrid because four reinforcement effects:

(1) Prevention of lateral spreading of aggregate

(2) Confinement of aggregate resulting in increased strength/stiffness of aggregate in the vicinity of the geogrid

(3) Reduction of vertical stresses on top of the subgrade

(4) Reduction of shear stress on the subgrade.

Despite many successful projects and research, it is recognized that the use of geogrid reinforcement in paved roadways is relatively limited compared to other geosynthetics applications.

It is recognized that the development of a design method within the framework of the mechanisticempirical design method will address the limitations of the current design approaches and lead to a broader use of geosynthetics in base reinforcement applications 


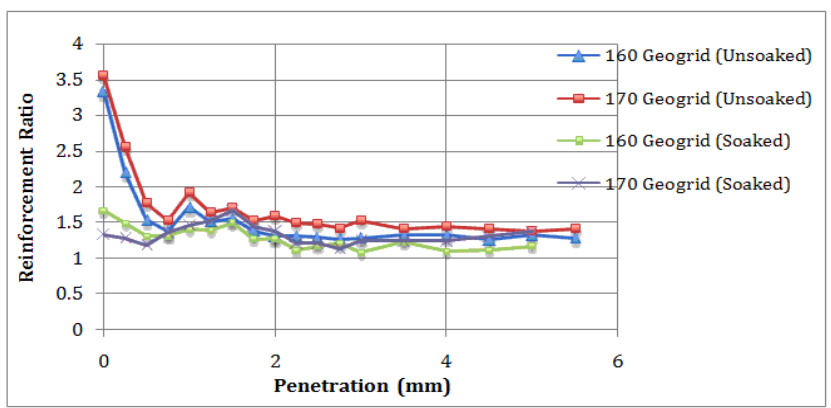

Fig 2 .Design of soil characteristics

\section{- Selection of material}

Selecting the suitable two different type material of material like (1) polymeric resin fibre material and (2) carbon fibre with polypropylene waste material both . in first material a fibre material with resin coating is tested and strength is checked. And in second material a carbon fibre is mixed with liquefied polypropylene recycle waste and strength is checked.

\section{- Selection of suitable site in which material is to be used as reinforcement}

Selecting a suitable site like roads, railway, bridge approach, retaining wall, embankment slope, sub grade soil foundation, etc. where it can be used to increase bearing capacity of soil

\section{- Selection of test to be performed}

To perform test using both material and avail the bearing capacity of soil, strength of reinforcement, lateral displacement of soil, binding property etc.

\section{- Compare both material}

To compare properties of both materials according to the test performed and find the suitable material among it.

\section{- Model of the best material among it}

To make a model comparing both materials according to its advantage and disadvantages.

\section{- Analysis}

After completion of the model we will find the strength of both materials according to test perform and analyse the result of each test and find which of the soil have good property as reinforcement which could help in stabilization of soil.

\section{TESTS RESULT AND CONCLUSION}

\section{CBR TEST RESULT:}

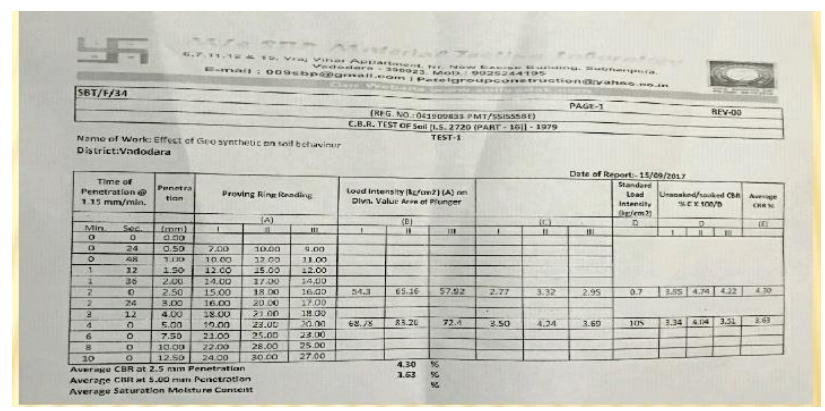

Fig 3. CBR result for sandy soil

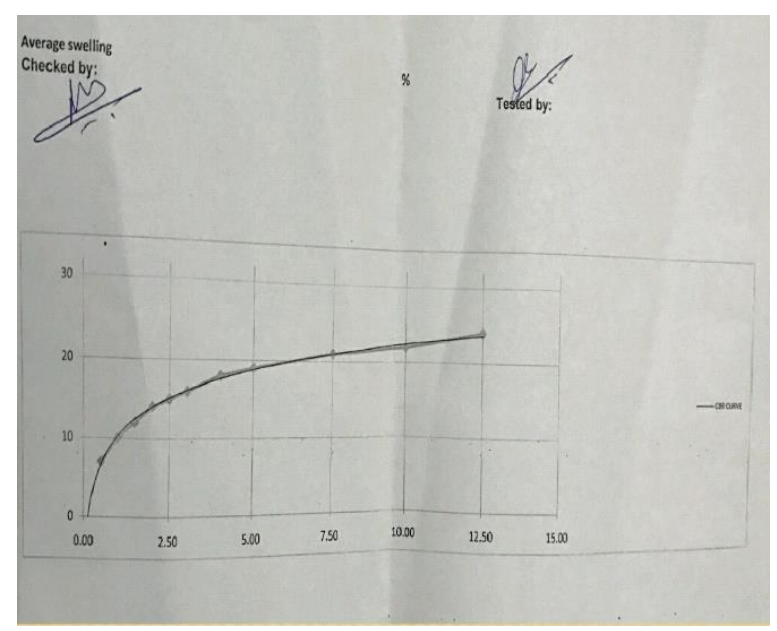

Fig 4. CBR result graph data PROCTOR COMPACTION TEST: -

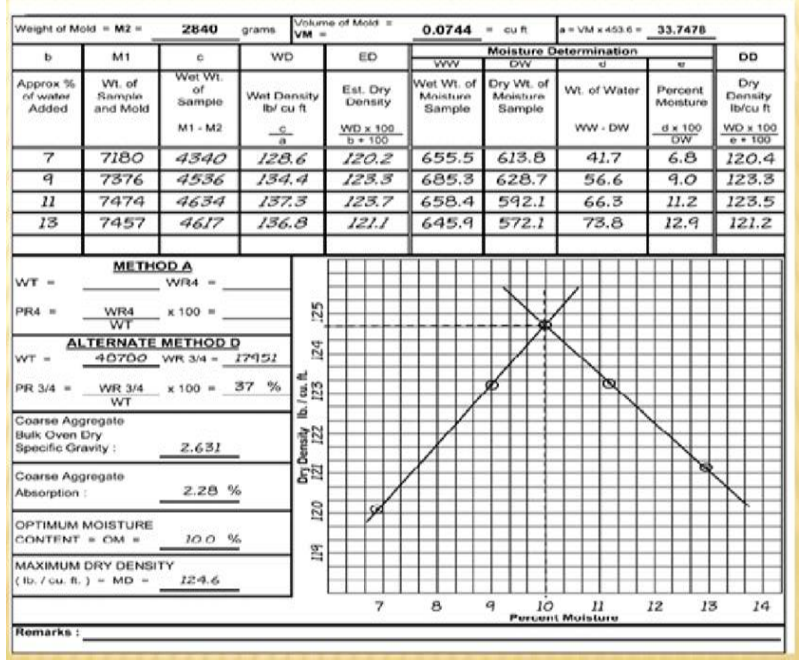

Fig 5 Proctor Compaction Test Result With Grip 
- The effect of reinforcement, plasticity index, and grading on strength enhancement of the compacted material was measured by CBR for soaked and unsoiled conditions. The results indicated that as soil plasticity increased due to increased fines fraction, the CBR decreased.

- The value of CBR is 4.30 for $2.5 \mathrm{~mm}$ penetration and 3.63 for $5 \mathrm{~mm}$ penetration which is perfect for soaked soil.

- In soil plasticity there is gradual increase in percentage of plasticity index from 9 to $27 \%$ and for soaked plasticity index should be above $20 \%$.

- There is gradual decrease in plastic limit from 25 to $20 \%$ which is good for cohesive soil to increase bearing capacity and strength of soil.

- The performance of soils in soaking condition can be improved using geo-grid. A maximum improvement up to 2.3 times and minimum of 1.7 is possible with geo-grid for the soaked performance.

- Bearing capacity is also dependent on U/B ratio; that is, bearing capacity is higher if the $\mathrm{U} / \mathrm{B}$ ratio is higher in proctor compaction test.

- The results of standard Proctor compaction test for silty clay soil is presented it is observed that the maximum dry unit weight and optimum moisture content (OMC) of the silty clay soil are $53.578 \mathrm{KN} / \mathrm{m} 3$ and $10 \%$, respectively.

- It is concluded that the bearing capacity of the silty soil can be improved by using the geogrid.

\section{REFERENCES}

[1]. International Journal of Emerging Research in Management \&Technology ISSN: 2278-9359 (Volume-2, Issue-5) "Geosynthetics Materials and Applications for Soil Reinforcement and Environmental Protection Works" by ANOOP SINGH

[2]. "Geosynthetics Materials and Applications for Soil Reinforcement and Environmental
Protection Works" BY Zhenqi CAI and Richard J. BATHURST Department of Civil Engineering, Royal Military College of Canada, Kingston, Ontario, Canada K7K 5LO

[3]. "Advances in Geosynthetic Reinforced Soil Design" by Dr. Jorge G. Zornberg, 2004 "GEOSYNTHETIC REINFORCEMENT OF THE AGGREGATE BASE/SUBBASE COURSES OF PAVEMENT STRUCTURES” BY Prepared by TenCateTM Geosynthetics North America 365 South Holland Drive Pendergrass, GA 30567

Cite this Article

Hemant Sharma, "The Effect of Geosynthetic Content on Soil Behaviour", International Journal of Scientific Research in Science and Technology (IJSRST), Online ISSN : 2395-602X, Print ISSN : 2395-6011, Volume 6 Issue 1, pp. 304-307, January-February 2019.

Available at doi :

https://doi.org/10.32628/IJSRST196141

Journal URL : http://ijsrst.com/IJSRST196141 